\title{
DECÁLOGO DA CLIMATOLOGIA DO SUDESTE BRASILEIRO
}

\author{
João Lima Sant'Anna Neto'
}

\begin{abstract}
RESUMO
Este artigo rediscute a climatologia regional do Sudeste brasileiro utilizando como estratégia, os dez mandamentos (ou dez características) fundamentais dos fatores e dinâmicas que explicam a sua gênese. Apóia-se no clássico trabalho de Edmon Nimer (1979) e em vasta bibliografia para colocar em discussão os princípios gerais e as particularidades dos climas regionais. Objetiva demonstrar como a localização, a rugosidade do relevo, a vasta zona costeira e os planaltos e vales interiores, inseridos num quadro de dinâmica atmosférica complexa, produz peculiaridades únicas, fazendo com que a região Sudeste do Brasil apresente uma das mais variadas gamas de tipos e subtipos climáticos.
\end{abstract}

Palavras chave: clima, climatologia regional, classificação climática, região sudeste, fatores do clima.

\section{THE TEN COMMANDMENTS OF THE SOUTHEAST BRAZILIAN CLIMATOLOGY}

\begin{abstract}
These paper discuss the southeast Brazilian climatology using as a strategy, the Ten Commandments (or ten characteristics) of factors and dynamics that explains its genesis. To support it, the major bibliography of climate studies, including Edmon Nimer (1979) classical text book was utilized to analyses general principles and particularities of regional climates. Aims to demonstrate how localization, relief altimetry, the vaster coastal zone, plains, highlands an interior valleys, introducing in a very complex schedule of atmospheric dynamics, produces unique peculiarities making the southeast Brazilian region presents one of the most varieties of climatic types.
\end{abstract}

Keywords: climate, regional climatology, climate classification, southeast region, climate factors.

\footnotetext{
${ }^{1}$ Professor Adjunto do Depto de Geografia da FCT/UNESP, Campus de Presidente Prudente, São Paulo, Brasil. E-mail: joaolima@fct.unesp.br
} 


\section{Introdução}

Desde o final de década de 1970 quando Edmon Nimer, geógrafo do IBGE publicou a "Climatologia do Brasil" (NIMER, 1979), que os estudos sobre os climas regionais deixaram de ser objeto principal de análise da Geografia brasileira. Chegava ao fim uma fase em que a perspectiva da regionalização, iniciada nas décadas de 1940/1950, a partir de políticas públicas, parecia esgotar-se.

De certa forma, o esforço em se conhecer, caracterizar e compreender a distribuição dos diversos climas do Brasil e sua dinâmica atmosférica, nesta ordem escalar, havia sido objeto de análise de vários estudiosos, cujos resultados satisfaziam as necessidades da época. Este fato pode ser observado nos trabalhos de Sampaio Ferraz (1934; 1939), Peixoto (1942), Schmidt (1942), Serebrenick (1942) Guimarães (1945), Serra (1942; $1945 ;$ 1946), Machado (1950), Monteiro (1951; 1962, 1963, 1969), Bernardes (1951), Guerra (1956), Barros (1957) e Nimer (1964, 1966, 1971), entre outros.

Entre os anos 1970 e a década de 1990, a maior parte dos estudos realizados no escopo da climatologia geográfica, direcionou-se para as análises do ritmo climático e da variabilidade dos elementos, notadamente das chuvas, muitos destes, aplicados as temática agrícola ou da organização do espaço como os de Tarifa (1973 e 1975), Conti, (1973), Toledo (1973), Santos (1976 e 1981), Câmara (1977), Barbiere (1979), Bernardes (1982), Sezerino (1982), Tetila (1983), Barrios (1987), Nunes (1990), Sant'Anna Neto (1990 e 1995), Zavattinni (1990) que buscaram compreender o ritmo dos climas locais, ou micro regionais (Ely, 2006).

A temática urbana, ainda que inicialmente contemplada desde o final da década de 1970 (Tavares, 1974; Sartori, 1979; Fonzar, 1981; Paschoal, 1981; Sampaio, 1981; Lombardo, 1984; Brandão, 1987; Danni, 1987), nos anos noventa é que numerosos os trabalhos sobre o desvendamento dos climas urbanos e voltados á análise episódica prevaleceram (Gonçalves, 1992; Castro, 1993; Salvi-Sakamoto, 1994; Zamparoni, 1995; Maitelli, 1994, Mendonça, 1994; Brandão, 1996; Alves Filho, 1996; Santos, 1996, Sette, 1996; Cabral, 1997; Heyer, 1997; Pitton, 1997; Tavares, 1997; Danni-Oliveira, 1999; Amorim, 2000; Mendonça, 2002) (Ely, 2006).

Neste longo período, entretanto, muitas foram as descobertas de processos e interconexões, ao nível da meteorologia, da dinâmica atmosférica, que trouxeram à luz novas perspectivas para a compreensão dos climas regionais, como por exemplo, as influências de fenômenos tais como o El niño/oscilação sul (ENOS), a zona de convergência do Atlântico Sul (ZCAS) e os complexos convectivos de meso-escala (CCM).

Além disto, com o aumento da densidade da rede de estações meteorológicas e as novas possibilidades de análise sobre a ciclicidade, periodicidade e variabilidade dos elementos do clima que as séries temporais, agora mais longas, passaram a permitir, tem-se uma boa oportunidade de se retomar os estudos regionais dos climas brasileiros.

\section{Antecedentes e Objetivos}

A região Sudeste do Brasil, sem dúvida alguma, se configura como uma das mais diversificadas, em termos climáticos, das regiões brasileiras. Para 
isto contribuem a sua localização latitudinal entre $15^{\circ}$ e $25^{\circ}$ sul, sua distribuição longitudinal, cuja área se estende da zona costeira atlântica até aproximadamente $1.000 \mathrm{~km}$ de distância do mar, sua altimetria e disposição do relevo.

Para demonstrar como estas peculiaridades influem e determinam os tipos climáticos, utilizaremos dez fatores ou processos que explicam esta enorme diversidade.

Desta forma propomos um decálogo (como os dez mandamentos) da climatologia da região Sudeste do Brasil, com o objetivo de caracterizar a natureza dos fenômenos naturais buscando uma explicação da diversidade dos climas regionais.

Toda a análise foi realizada a partir dos dados de informação dos elementos meteorológicos e, foram obtidos junto ao INMET (Instituto nacional de Meteorologia) e ao CEPAGRI (Centro de Pesquisas na Agricultura). Foram tabulados e calculados utilizando-se das normais climatológicas do período 1961/1990 e dados de 1991 a 2000.

Segundo o Instituto Brasileiro de Geografia e Estatística (IBGE, 2006), a região sudeste do Brasil apresenta 14 subtipos climáticos regionais. Utilizando como critérios básicos as temperaturas médias e o regime pluviométrico (volume anual e distribuição sazonal), os tipos climáticos podem ser agrupados em três grandes conjuntos, como se pode observar na figura 1.

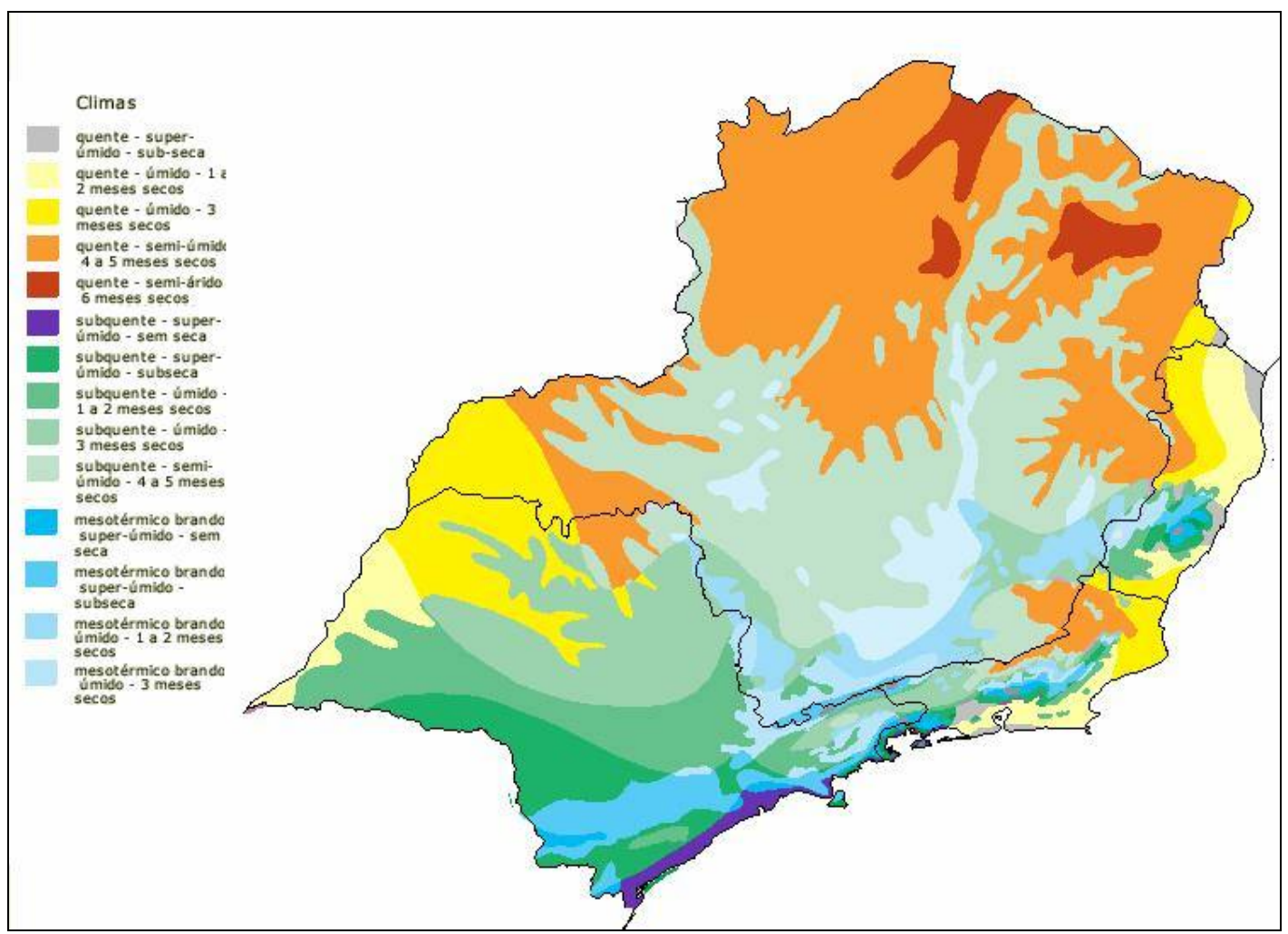

Figura 1. Tipos climáticos da região Sudeste, segundo o IBGE (2006).

O primeiro grupo caracteriza-se por climas quentes, subdivididos em 5 variações em função da distribuição pluvial: dos superúmidos (sem estação seca) aos semi-áridos (com até 6 meses secos), localizados basicamente no 
norte do Estado de Minas Gerais, Triângulo Mineiro, Oeste e Norte Paulista, litoral e Norte Fluminense, além de praticamente todo território capixaba, à exceção da região serrana.

O segundo grupo, denominado de subquente apresenta temperaturas médias ligeiramente inferiores, pelo efeito da altitude, mas com características pluviométricas semelhantes, variando do superúmido até áreas com 4 a 5 meses secos, localizados principalmente no Centro-sul mineiro e centro-oeste paulista.

Nas latitudes mais altas e nas áreas mais elevadas, encontram-se os subtipos climáticos do terceiro grupo: os mesotérmicos, cujas temperaturas são mais brandas e distribuição sazonal mais uniforme das chuvas, que ao contrário dos dois grupos anteriores, apresentam período seco menos prolongado.

\section{O Decálogo}

\section{Uma posição latitudinal peculiar}

(como a extensão norte/sul produz uma variada gama de climas regionais)

A região Sudeste do Brasil localiza-se quase que em sua totalidade, na região tropical, excetuando-se uma pequena faixa no sul do estado de São Paulo. Estende-se entre as latitudes $14^{\circ}$ e $25^{\circ}$ sul, abrangendo uma vasta área de aproximadamente um milhão de quilômetros quadrados (figura 2).

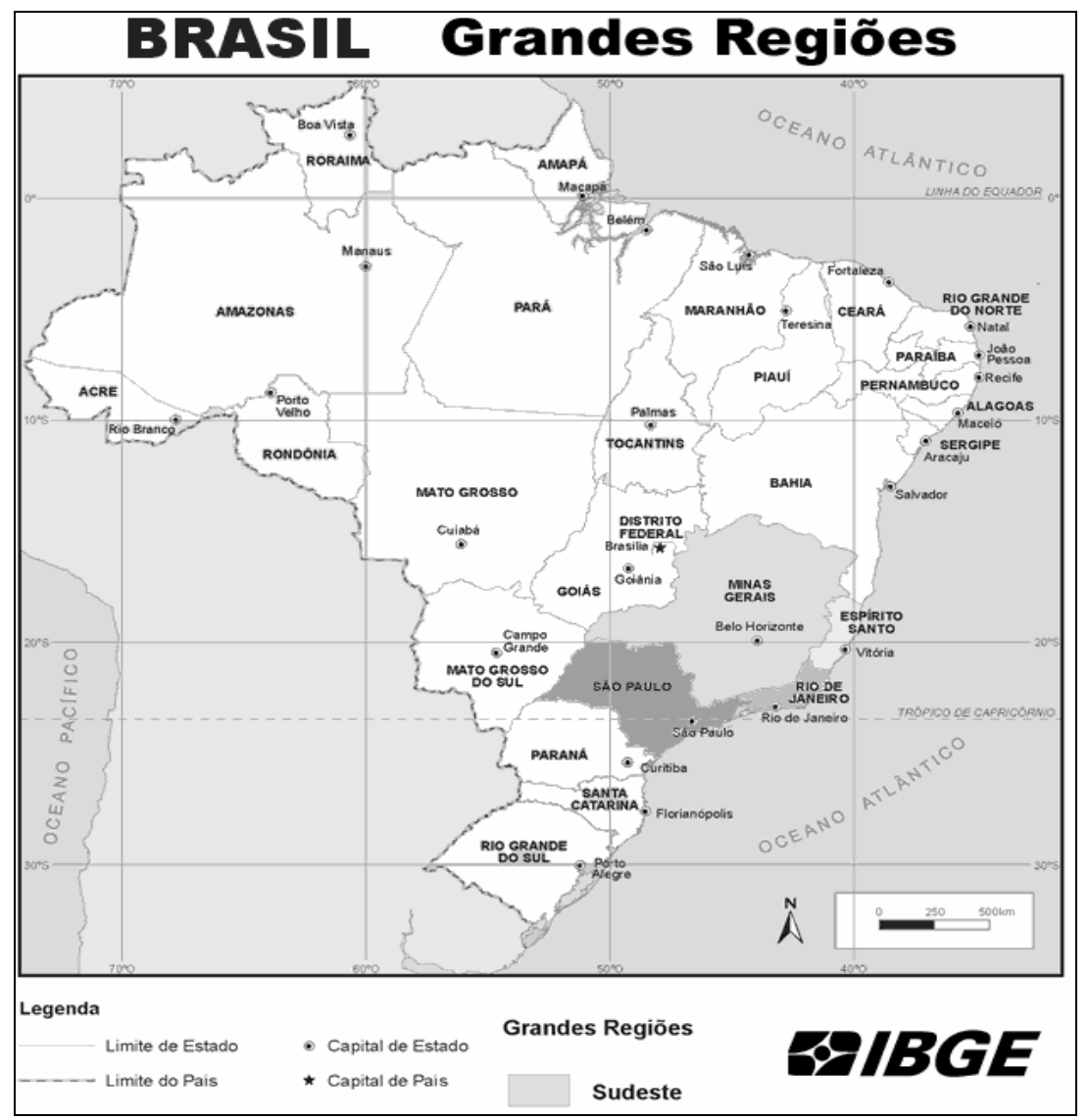

Figura 2. Localização geográfica da região Sudeste no Brasil (IBGE, 2006). 
Ao norte apresenta características típicas do clima semi-árido do sertão nordestino, cujos totais anuais não ultrapassam os $800 \mathrm{~mm}$ de chuva e o regime pluviométrico constitui-se em longos períodos de estiagem que podem durar 5 ou 6 meses, como no norte mineiro, nas regiões de Januária, Montes Claros e Vale do Jequitinhonha.

Ao sudeste, notadamente no litoral paulista, encontra-se o clima superúmido, sem estação seca, em que os totais anuais de precipitação podem superar os $3.000 \mathrm{~mm}$, como na região de Maresias e de Ubatuba.

Climas com temperaturas mais brandas, como o sub-tropical, são encontrados no extremo sul paulista, nas regiões de Itapeva e Capão Bonito.

Desta forma, os climas latitudinais da região Sudeste, apesar de tipicamente tropicais, apresentam significativas variações térmicas e pluviométricas em grande parte explicadas pela grande extensão norte/sul que produz, à medida que a latitude aumenta, diminui a temperatura e, aumentam os totais anuais de precipitação.

\section{O predomínio das "terras altas": uma topografia acidentada}

(a altitude como fator de "abrandamento" do caráter tropical do clima)

Desde a publicação do celebre trabalho de De Martonne (1944), sobre os problemas morfológicos do Brasil Tropical Atlântico, que o efeito orográfico nos climas regionais do país passou a ser considerado de forma mais presente. Nenhuma outra região brasileira apresenta uma influência tão nítida e marcante da altimetria e disposição do relevo nas configurações dos climas regionais. Estudos clássicos, ainda que focando áreas mais restritas, como os de Ab'saber (1967), França (1946), Nimer (1971), Monteiro (1967 e 1973), Conti (1975), entre outros, demonstraram o papel do relevo e da altitude na distribuição espacial das chuvas e nas condições térmicas.

É fato que grande parte do território compreendido pelos estados do Sudeste encontra-se no Planalto Atlântico, em altitudes superiores a 500 metros (cerca de $80 \%$ da região). Nada menos do que $20 \%$, inclusive, em altitudes maiores do que 800 metros (figura 3).

Além disto, o vasto litoral que se estende por mais de $1.500 \mathrm{~km}$ de norte a sul na costa leste, permite a penetração de ventos alísios, constantes e responsáveis por farta alimentação de umidade nas vertentes a barlavento.

A presença das serras do Mar, da Mantiqueira, do Espinhaço, dos Órgãos, da Canastra e de Caparaó, quase todas dispostas no sentido norte/sul, a despeito de produzir um clima tropical de altitude, por seu efeito nas temperaturas, também exercem importante papel da distribuição espacial das chuvas, gerando "ilhas" úmidas nas vertentes leste e sudeste e, "ilhas" secas (ou sombras de chuva) nas vertentes oeste e norte.

Nas porções mais elevadas da serra da Mantiqueira, com altitudes superiores a 1.500 metros, como em Campos do Jordão (SP) ou em Itatiaia $(R J)$, o efeito altimétrico determina temperaturas mínimas frequentemente inferiores a zero grau nos invernos, inclusive com a presença de neve, em não raros episódios. Por outro lado, nos vales fluviais interiores, de altitudes mais modestas, inferiores a 500 metros, as temperaturas máximas de verão ultrapassam os $40^{\circ} \mathrm{C}$ com freqüência.

No que concerne a pluviometria, esta disposição longitudinal das principais estruturas morfológicas do relevo, como a vertente atlântica da serra do Mar, induz uma precipitação acumulada anual de mais de 3.000 mm, e em 
anos excepcionalmente chuvosos, superior a $4.000 \mathrm{~mm}$, como em 1976, $1983 \mathrm{e}$ 1995. Nas vertentes a sotavento, entretanto, as chuvas não alcançam 2.000 $\mathrm{mm}$. Assim, esta disposição geral das serras no sentido norte-sul, facilita a penetração do ar polar e serve de obstáculo às correntes de leste. Entre as grandes serras (do Mar, Mantiqueira e Espinhaço), aparecem vales amplos e muito rebaixados, que aumentam a turbulência do ar, gerando uma enorme variedade de tipos climáticos.

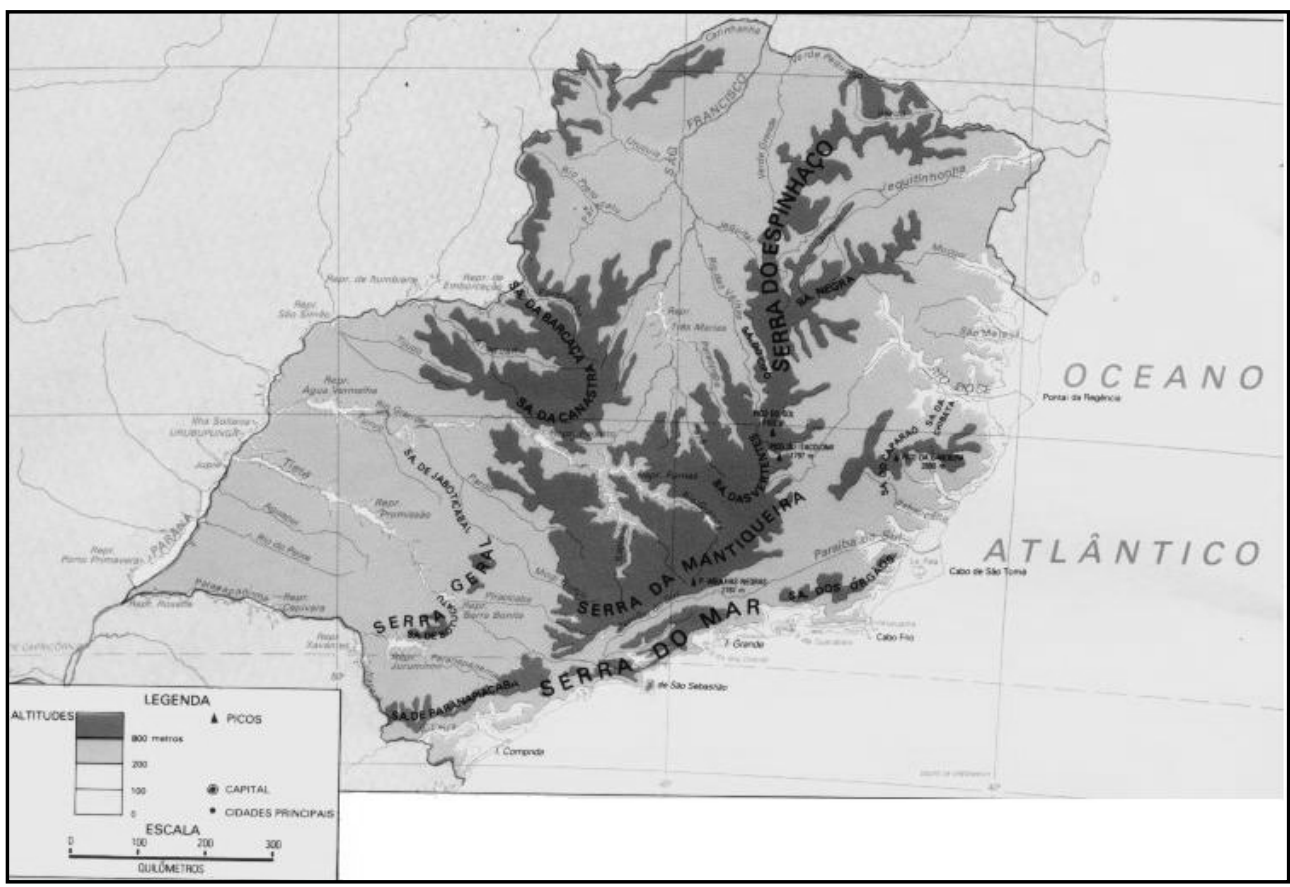

Figura 3. Altimetria e principais serras da região Sudeste (IBGE, 2006).

\section{O palco de um conflito anunciado}

(como as correntes perturbadas eliminam a estabilidade do ar tropical)

A dinâmica atmosférica característica da região Sudeste apresenta duas situações distintas. No verão há o predomínio das correntes de leste, originadas pelo deslocamento dos ventos alísios, materializadas na baixa troposfera pela massa tropical atlântica. Este sistema produz estabilidade do tempo e, à medida que penetra pelo interior da região, pelo efeito adiabático, provoca elevação das temperaturas e diminuição da umidade em sua trajetória. Em função da grande rugosidade do relevo, a cada vertente a barlavento, este sistema atmosférico deixa parte da umidade e, ao transpor-las provoca ressecamento adiabático nas vertentes a sotavento, além de aquecimento nos vales encaixados.

Assim, por exemplo, ao chegar ao litoral paulista, a massa tropical atlântica encontra a íngreme escarpa da serra do Mar. Ao ultrapassar este obstáculo natural, produz aumento da umidade, da nebulosidade e mesmo das precipitações, assim como, determina a queda da temperatura. Ao descer as encostas a sotavento, no Vale do Paraíba e na Bacia Paulistana, cerca de 300 a 400 metros mais baixos acarreta, pelo mesmo efeito adiabático, ressecamento da umidade e aquecimento da temperatura. 
Continuando sua trajetória leste/oeste algumas dezenas de quilômetros adiante, encontra novo obstáculo representado pelas serras da Mantiqueira e da Cantareira/Japi. Novamente, ao subir perde mais umidade e provoca a queda ainda mais acentuada da temperatura. Ao atingir a Depressão Periférica e a Zona da Mata Mineira, no rebordo serrano, o ar fica mais seco e quente. Em resumo, a configuração do relevo e o efeito da continentalidade do sudeste brasileiro são fundamentais na determinação da diminuição da umidade e do aumento da temperatura da zona costeira, a leste, em direção ao interior, a oeste.

As correntes de sul, por seu turno, particularmente a penetração do anticiclone polar atlântico provoca a formação de extensas zonas de perturbação frontal, no contato com as massas tropicais (de leste e norte) e as equatoriais (de noroeste e oeste), produtoras de quase $2 / 3$ da gênese pluvial dos estados do sudeste.

Estas correntes, acrescidas da umidade do oceano e da região amazônica que chegam à região, despejam chuvas de primavera/verão, que decrescem de sul para norte, ainda que ilhas úmidas surjam em função da rugosidade do relevo. Este fato, associado ao processo descrito anteriormente sobre o efeito da continentalidade e disposição das vertentes, pode ser observado na figura 4.

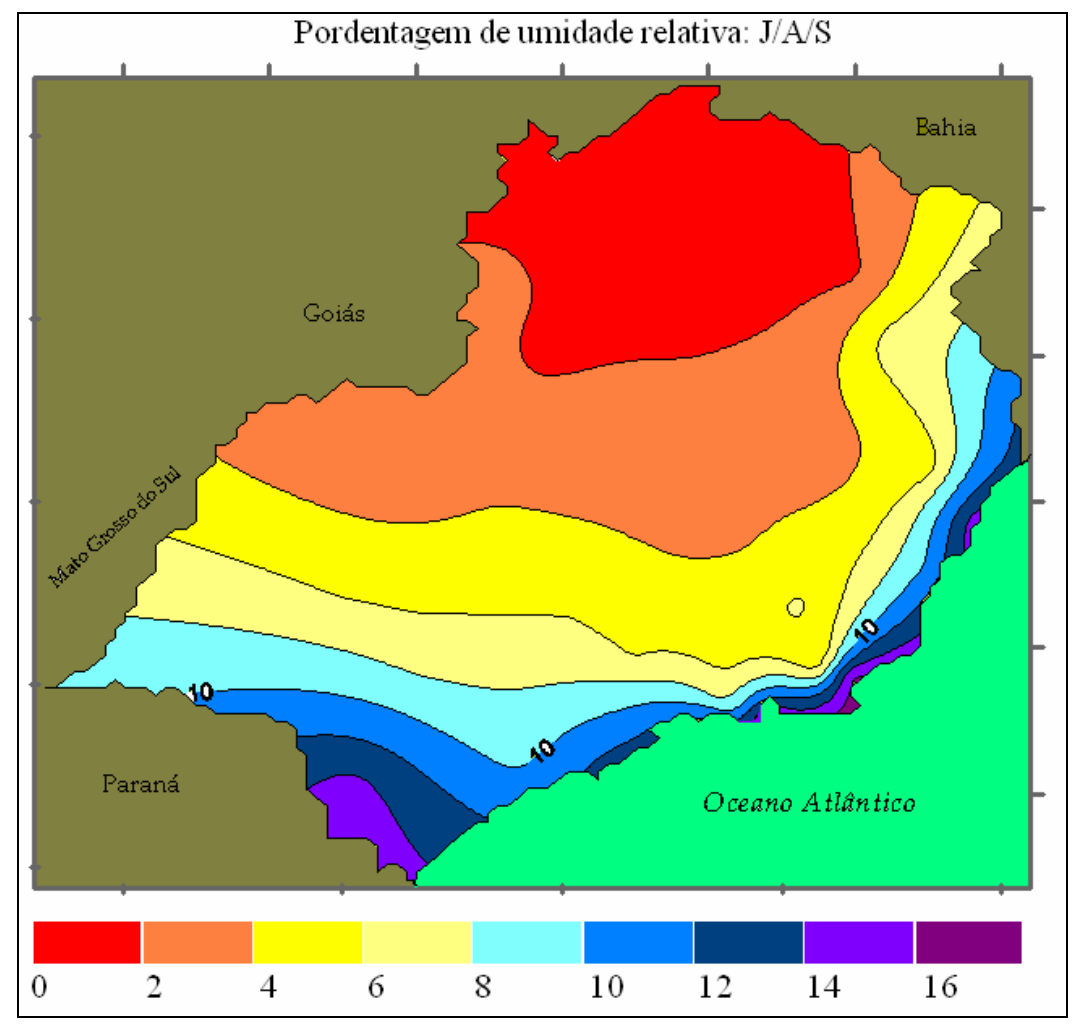

Figura 4. Umidade relativa (em \%) no trimestre seco (Sant'Anna Neto, 2004).

No período de primavera/verão, o anticiclone migratório polar é responsável pelo avanço das frentes frias que atuam na região, por mecanismos de circulação superior do ar e pelo deslocamento do equador térmico para o hemisfério norte. No outono/inverno, os bloqueios das frentes 
tornam-se mais frágeis e o anticiclone polar avança para latitudes mais baixas, deixando terreno para a evolução da massa polar, que traz episódios de temperaturas mais frias.

\section{Os moventes e as interações}

(ou como os sistemas singulares produzem dinâmicas complexas)

Além dos sistemas atmosféricos da baixa troposfera, como as massas de ar e as frentes, outros sistemas são responsáveis por perturbações e instabilidades. As ZCAS (Zona de Convergência do Atlântico Sul) resultantes do corredor de umidade da massa equatorial continental, no sentido noroeste/sudeste, alimentam e intensificam a perturbação frontal, notadamente nos estados de São Paulo e Minas Gerais. Além destes, também atuam na região as linhas de instabilidade do ar tropical e os Complexos Convectivos de meso-escala (CCM's). As linhas de instabilidade ocorrem principalmente no encontro do ar úmido do oceano com o ar seco do continente e os CCM's, da depressão do Chaco, sobre o oeste paulista (figuras 5, 6a e 6b, 7 e $8 \mathrm{a}$ e 8b).

(a) Posição Média Anual

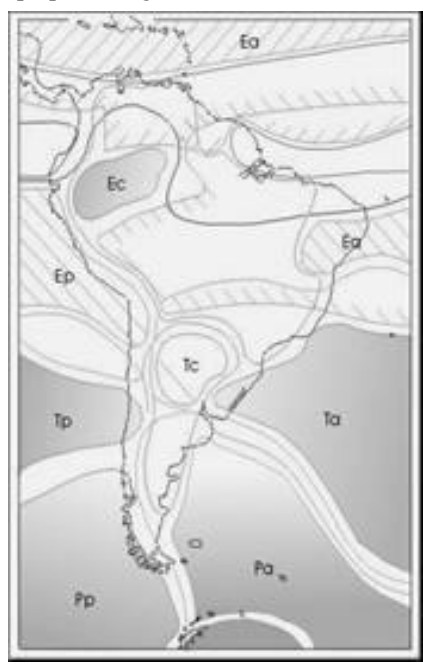

(b) Posição Média de Verão

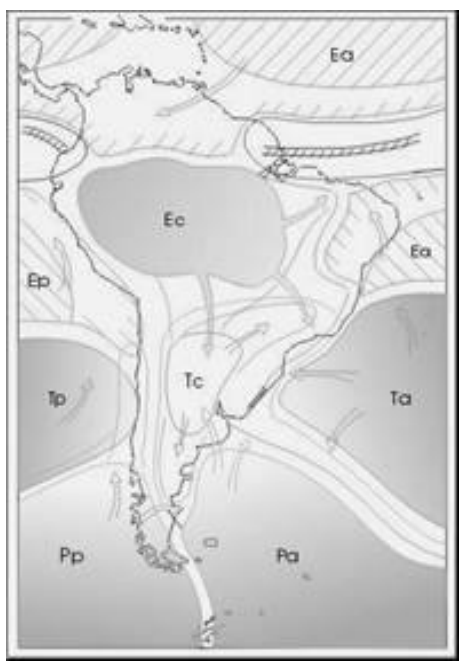

(c) Posição Média de Inverno

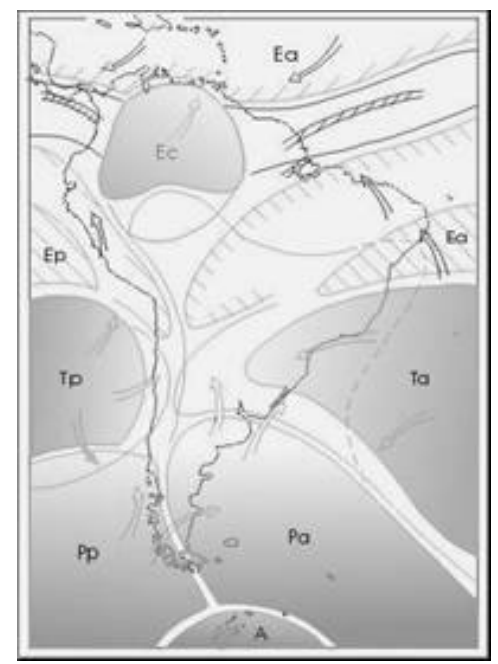

Figura 5. Situação habitual dos sistemas atmosféricos na América do Sul.

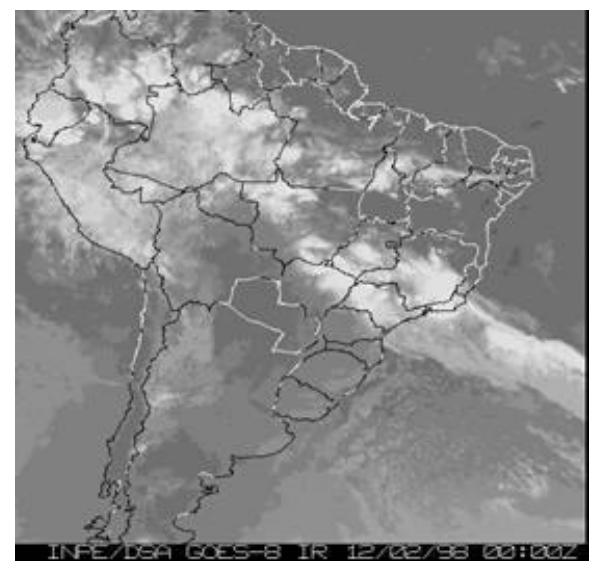

Figura 6a. Atuação das ZCAS.

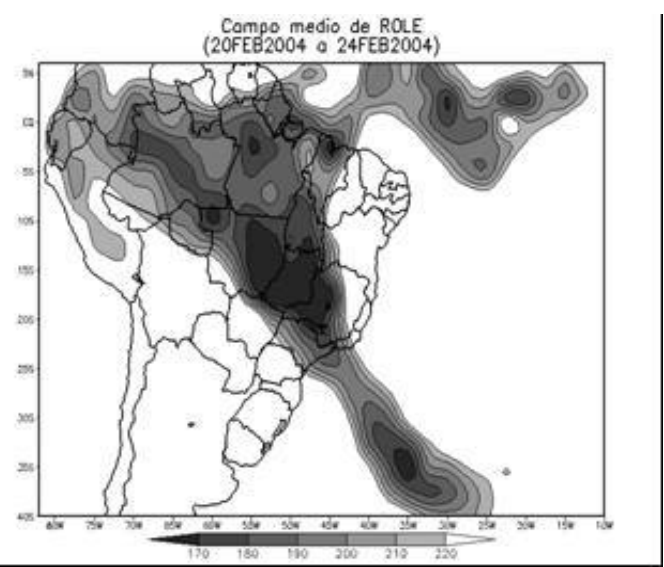

Figura 6b. Configuração de uma ZCAS. 

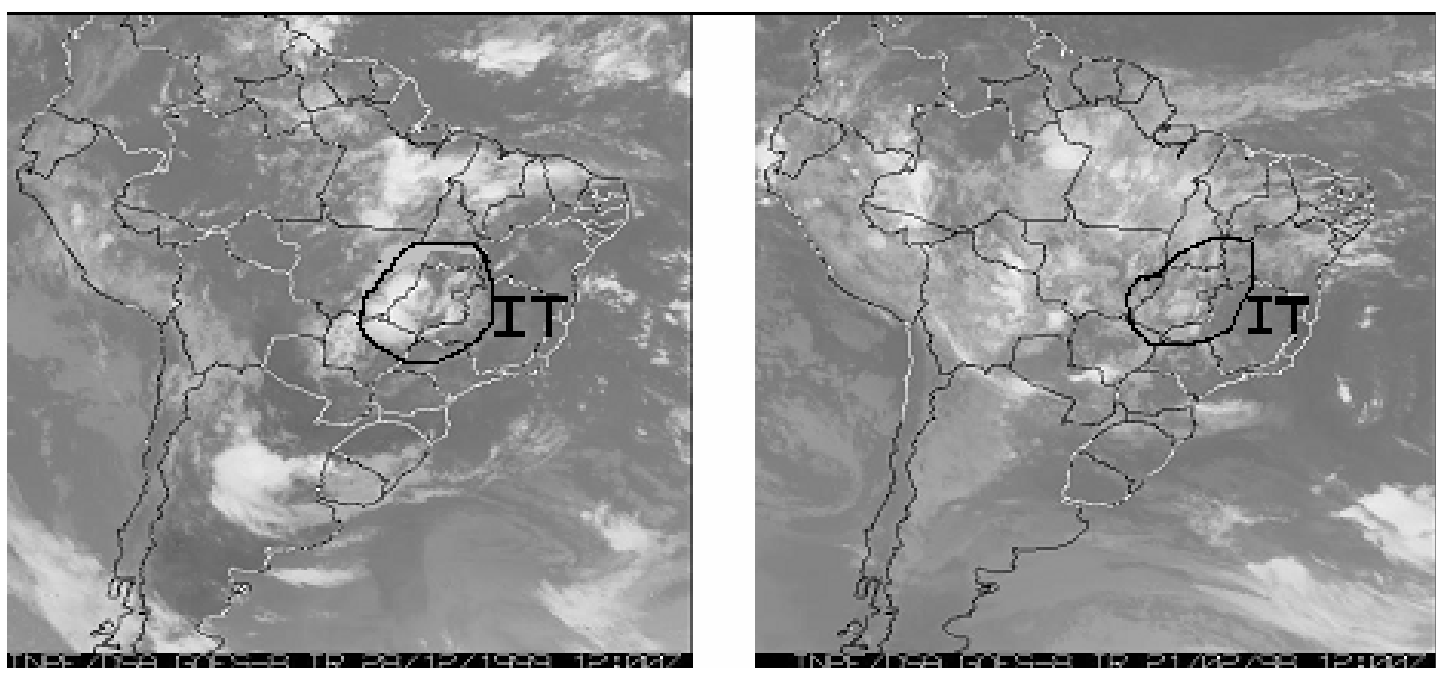

Figura 7. Linhas de instabilidade tropical.

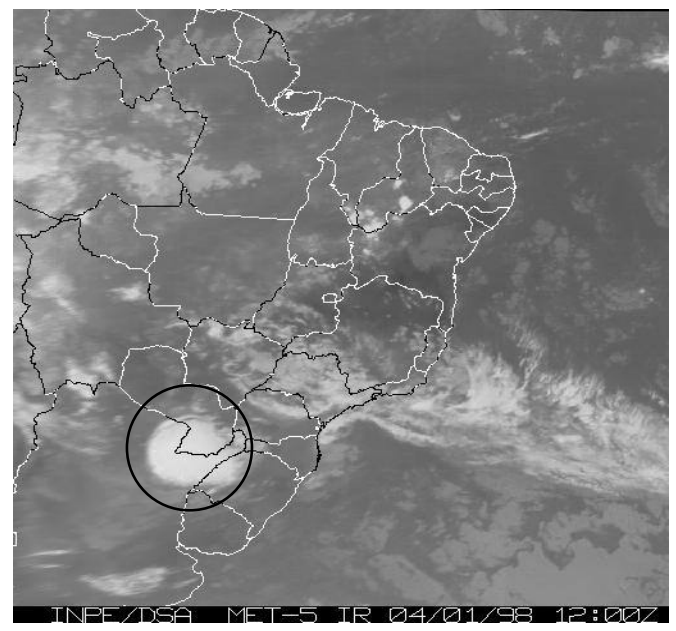

Figura 8a. CCM's sobre o Paraguai.

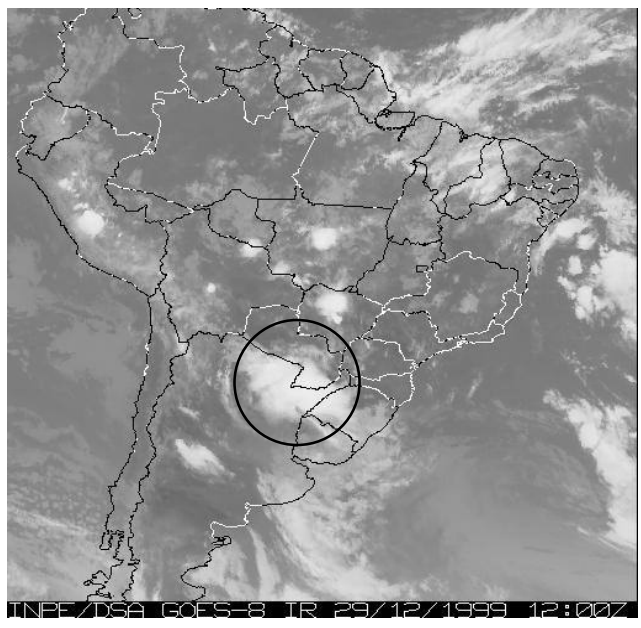

Figura 8b. CCM's sobre o Paraguai.

\section{Um mar que não é para todos}

(ou o efeito da continentalidade para alguns)

A zona costeira da região Sudeste apresenta uma característica marcante, pois, de sul para o norte a pluviosidade é distribuída de maneira desigual. De Cananéia no extremo sul até Ubatuba, na latitude do Trópico de Capricórnio, as chuvas são abundantes sem um período de seca. No litoral do Rio de Janeiro até Cabo Frio, as precipitações diminuem tornando a aumentar no litoral capixaba, entre Vitória e São Mateus, como demonstra a Figura 9.

A fachada atlântica do Sudeste brasileiro, entretanto, é margeada por serras elevadas (em torno dos 1.000 metros) que recebem os ventos úmidos do oceano e, pelo efeito orográfico, incrementa as chuvas locais. Ultrapassada esta barreira costeira, as precipitações diminuem gradativamente, na direção leste/oeste, como mostra a figura 10, representativa do transeto 
Ubatuba (SP)/Capinópolis (MG), em função da continentalidade e da rugosidade do relevo.

Desta forma, a maritimidade acrescida dos ventos alísios do anticiclone tropical atlântico, são responsáveis pela maior precipitação costeira e progressiva diminuição no sentido leste/oeste pelo efeito da continentalidade.

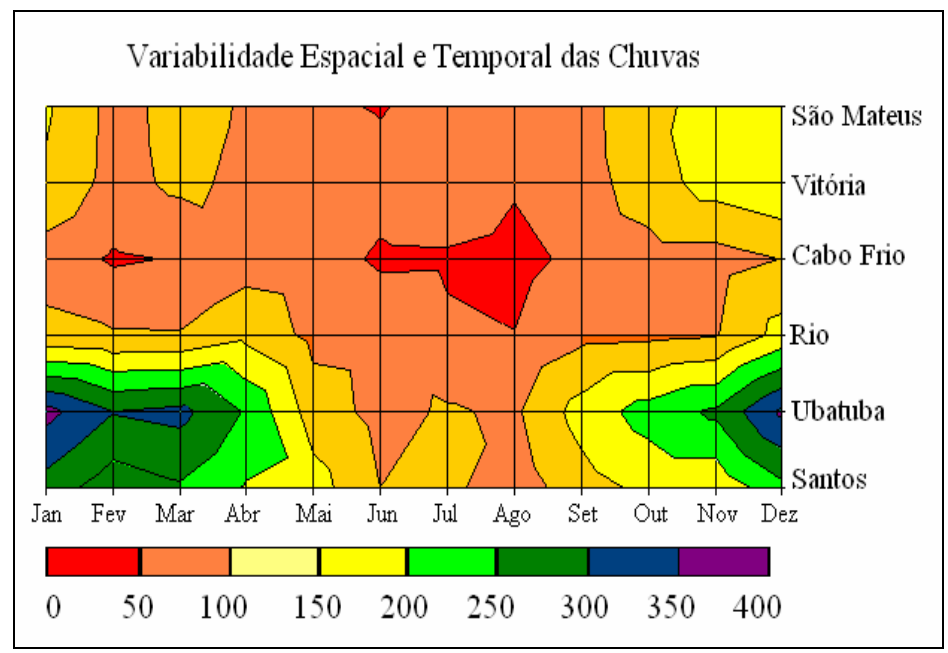

Figura 9. Variabilidade das chuvas no litoral.

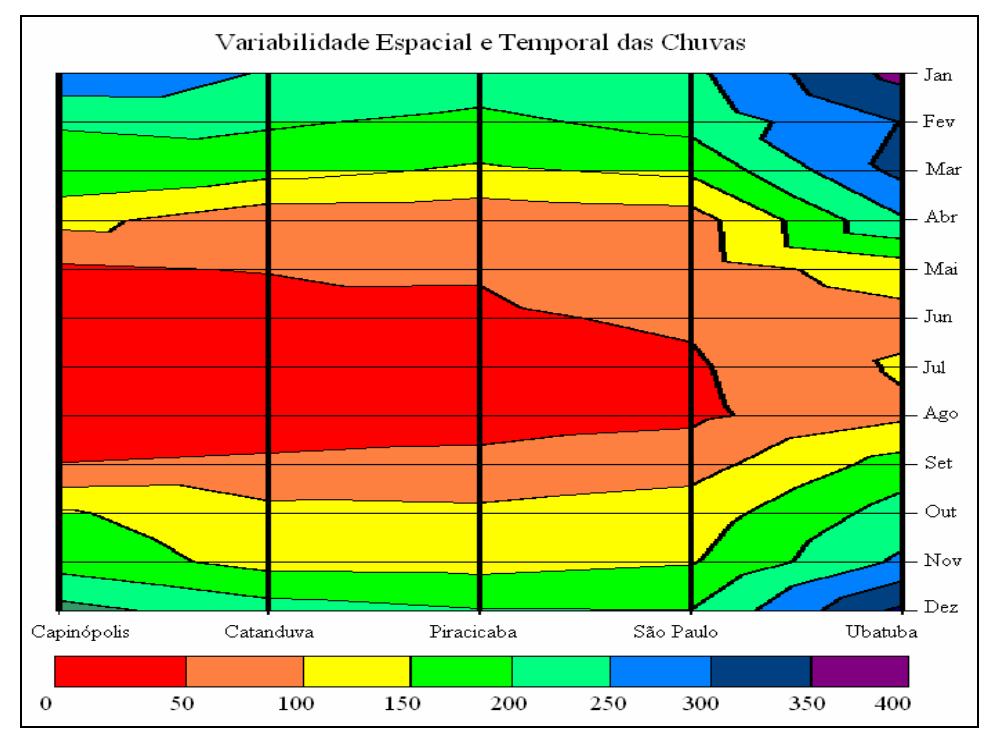

Figura 10. Efeito da continentalidade.

\section{Uma chuva que não sabe chover}

(ou, a enorme diversidade espaço/temporal da pluviosidade)

Entre os mais de $4.000 \mathrm{~mm}$ de chuvas anuais da vertente atlântica da serra do Mar no estado de São Paulo (Maresias a Ubatuba) e os menos de $800 \mathrm{~mm}$ no norte mineiro, a precipitação da região Sudeste apresenta uma significativa variabilidade espacial. 
De forma geral, uma faixa no sentido SE/NO, partindo do litoral paulista e o alinhamento das serras da Mantiqueira e da Canastra, incluindo o planalto sul mineiro são as áreas mais regadas pelas chuvas, em parte pela latitude do trópico de Capricórnio, que também funciona como equador térmico no verão, provocando episódios de frentes estacionárias e dissipadas, aumentando o volume de chuvas sazonais. Por outro lado, a presença das elevadas altitudes do relevo incrementam as chuvas orográficas transformando estas áreas nas de maior pluviosidade.

Tanto ao norte/nordeste, quanto ao sudoeste da região, os volumes de precipitação diminuem acompanhando os fuxos de domínio do ar tropical (ao norte) e polar (ao sul). Tal característica também ocorre nas baixas altitudes e presentes nas planícies e vales dos grandes rios (figura 11).

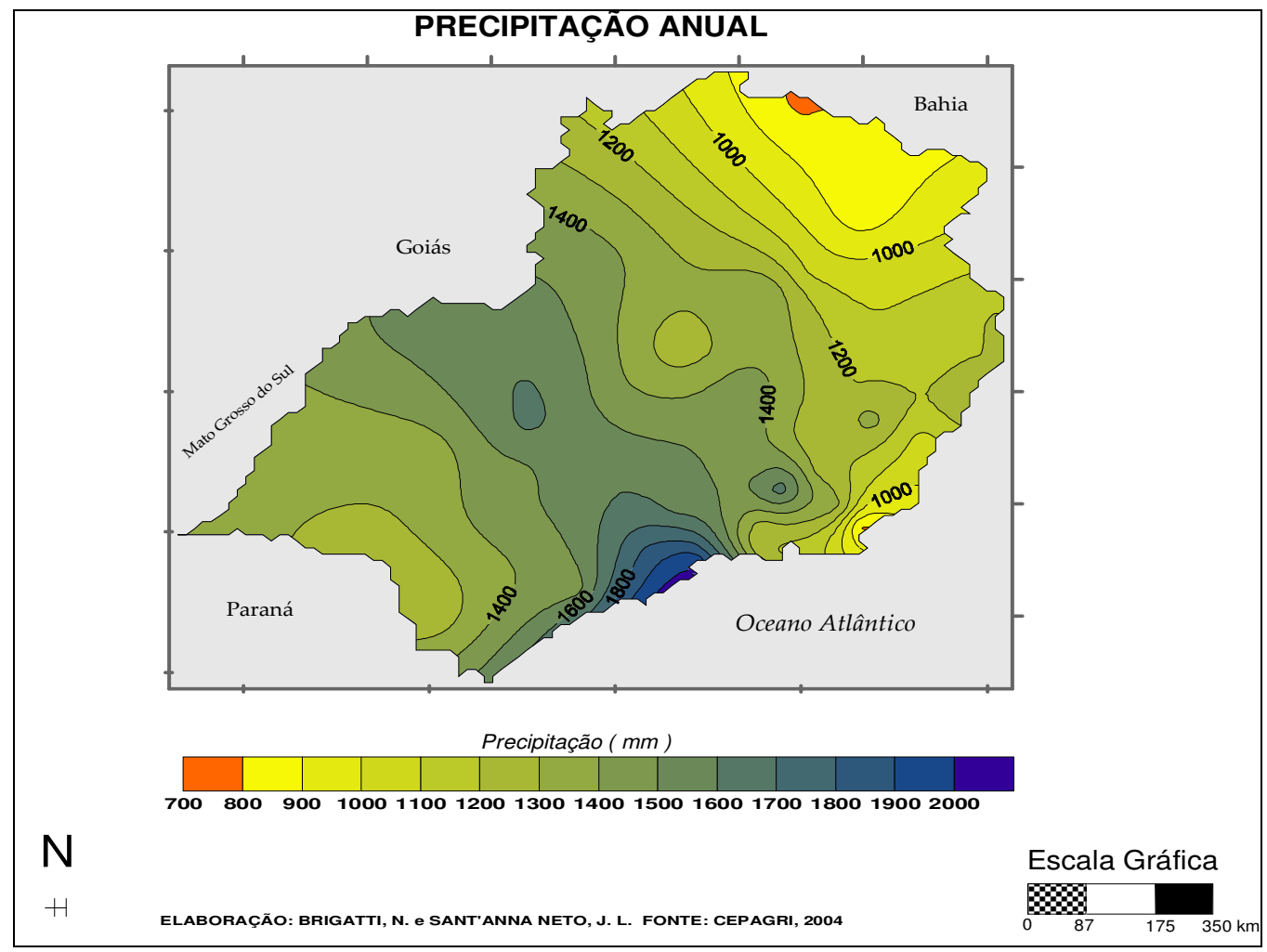

Figura 11. Distribuição pluviométrica anual da região Sudeste.

A variabilidade temporal também se manifesta sazonalmente de forma bastante diversificada. A concentração pluvial no trimestre mais chuvoso ocorre exatamente onde os totais anuais de chuvas são os mais modestos, no norte de Minas Gerais. Nesta região, cerca de $50 \%$ a $60 \%$ do volume anual se concentra em apenas 3 meses. Consequentemente, nestas áreas verificam-se forte período de estiagem no trimestre mais seco, quando menos de $5 \%$ das chuvas ocorrem.

Em ambos os casos, a tendência geral da diminuição das chuvas e de concentração pluvial, seguem a direção do litoral, a sudeste, para o norte de Minas Gerais, excetuando-se a região serra na porção central da região, como demonstram as figuras 12 a e b. 
Estes fatos demonstram a grande desigualdade na distribuição espacial e temporal das chuvas, explicada pela dinâmica atmosférica em associação com a configuração do relevo e os fatores geográficos, como a continentalidade e altimetria.

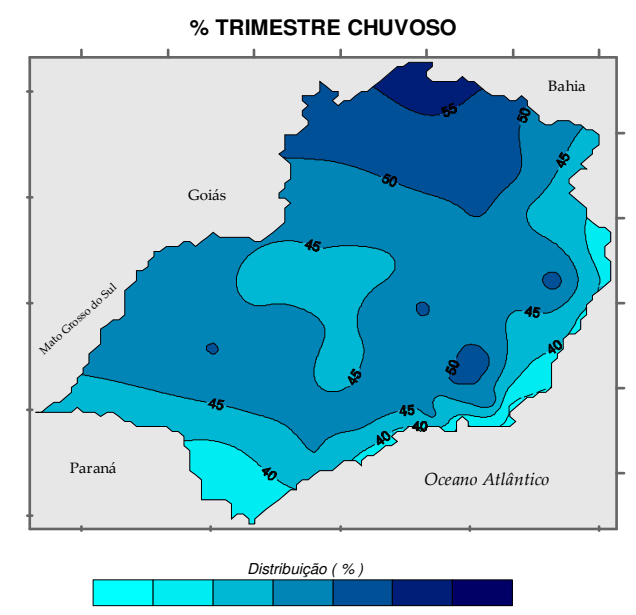

Figura 12a. Concentração pluvial no trimestre chuvoso.

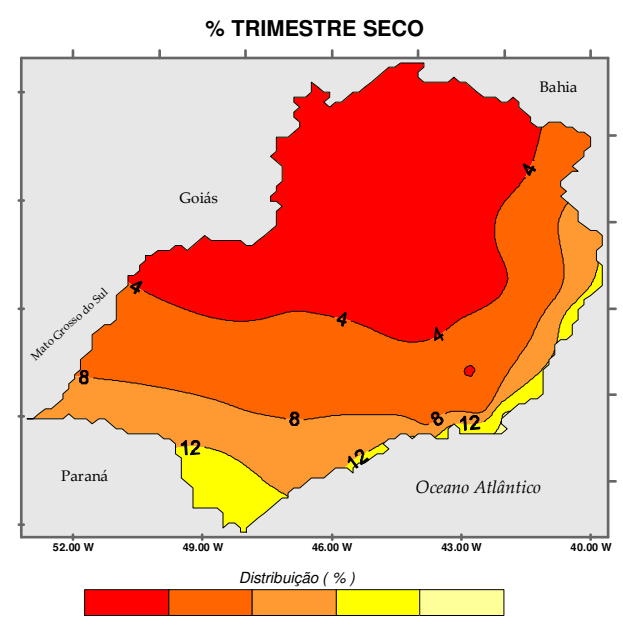

Figura $12 \boldsymbol{b}$. Concentração pluvial no trimestre seco.

\section{0 calor que arde e o frio que congela} (ou o exagero da amplitude térmica regional)

As diferenças térmicas regionais são, assim como as pluviométricas, extremamente diversificadas. A grande extensão latitudinal associada às elevadas altitudes do relevo exercem importante papel na distribuição das temperaturas médias anuais. Estas variam entre $14^{\circ} \mathrm{C}$ e $25^{\circ} \mathrm{C}$. Mais elevadas no norte de Minas Gerais e no litoral leste (RJ e ES) e, menores no sul e na região serrana (figura 13 ).

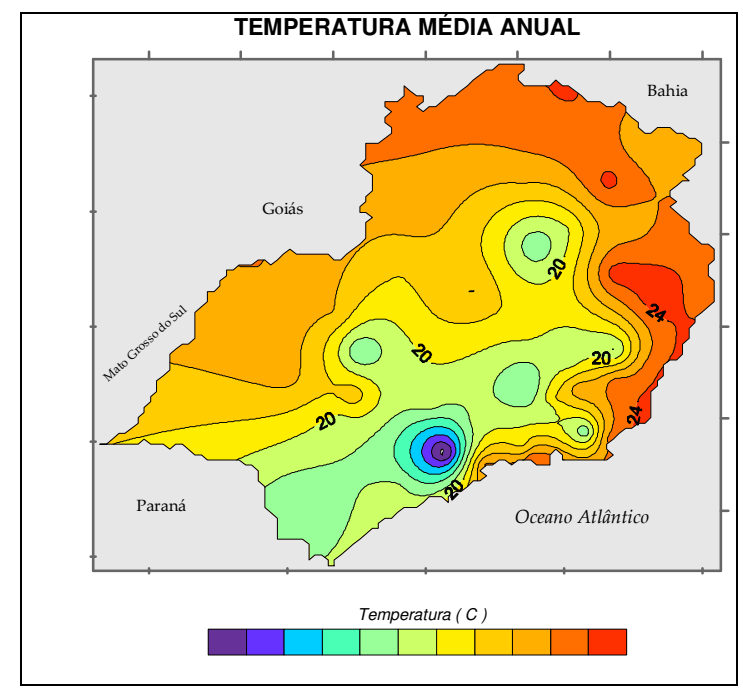

Figura 13. Temperatura média anual da região Sudeste. 


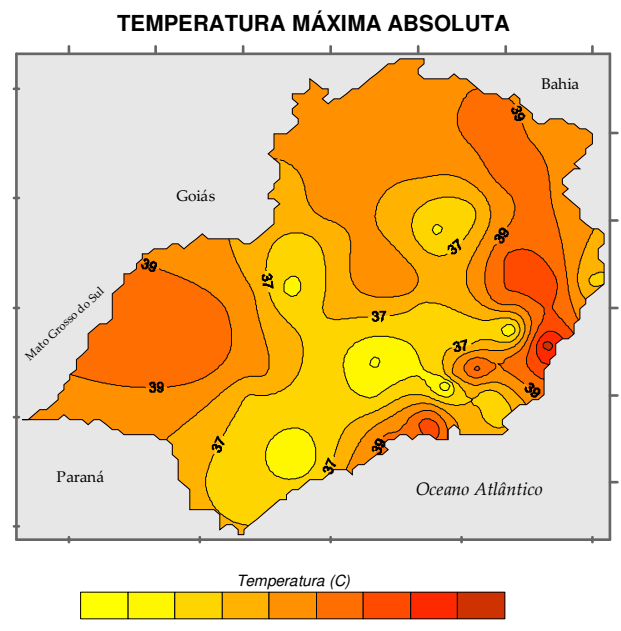

Figura 14a. Temperaturas máximas absolutas.

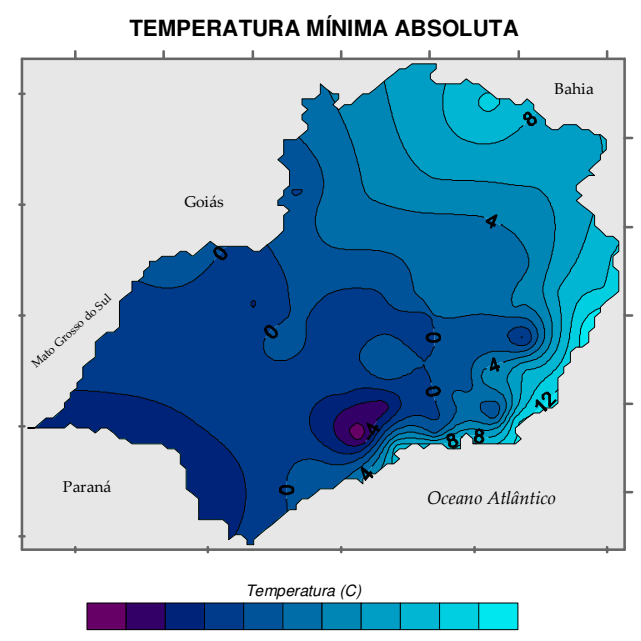

Figura 14b. Temperaturas mínimas absolutas.

Mais impressionante ainda, é a amplitude térmica entre as máximas e mínimas absolutas, que chegam a atingir quase $50^{\circ} \mathrm{C}$ de diferença. Na serra da Mantiqueira, os invernos são bastante rigorosos para as latitudes tropicais, onde já foram registradas temperaturas próximas dos $-10^{\circ} \mathrm{C}$. Por outro lado, os verões, muito quentes, apresentam valores superiores aos $40^{\circ} \mathrm{C}$ no norte $\mathrm{e}$ nordeste de MG, no litoral do ES, RJ, além do oeste paulista (figuras $14 a$ e b).

\section{Sobre os verões e invernos}

(uma estacionalidade comprometida)

Um dos aspectos mais marcantes dos climas tropicais é que a sazonalidade anual caracteriza-se mais pela concentração pluvial do que pela variação térmica. Na região Sudeste, entretanto, ambas exercem importante papel na configuração estacional.

O verão austral ocorre entre outubro e março, período este em que as chuvas são abundantes e as temperaturas mais elevadas. Em função da configuração do relevo, as áreas de maior altitude apresentam precipitação mais elevada e temperaturas médias mais baixas. Assim, na região sudeste, enquanto o norte/nordeste de MG, o noroeste de SP e o vale do Jequitinhonha (incluindo o norte do ES) caracterizam-se por menores totais de chuvas e maiores temperaturas, as áreas serranas, notadamente as serras do Mar, da Mantiqueira e da Canastra, com altitudes superiores a 1.000 metros (em alguns pontos, mais de 1.500 metros) as precipitações são mais abundantes e a temperatura mais baixa, conforme está demonstrado na figura 15.

\section{Um ano não é igual a outro}

(a falsidade dos padrões normais)

A localização geográfica da região Sudeste, entre as áreas de domínio dos climas Semi-árido ao norte, Tropical típico ao oeste e Subtropical 
ao sul, contribui decisivamente para a existência de uma variada gama de tipos climáticos, como já foi observado anteriormente.
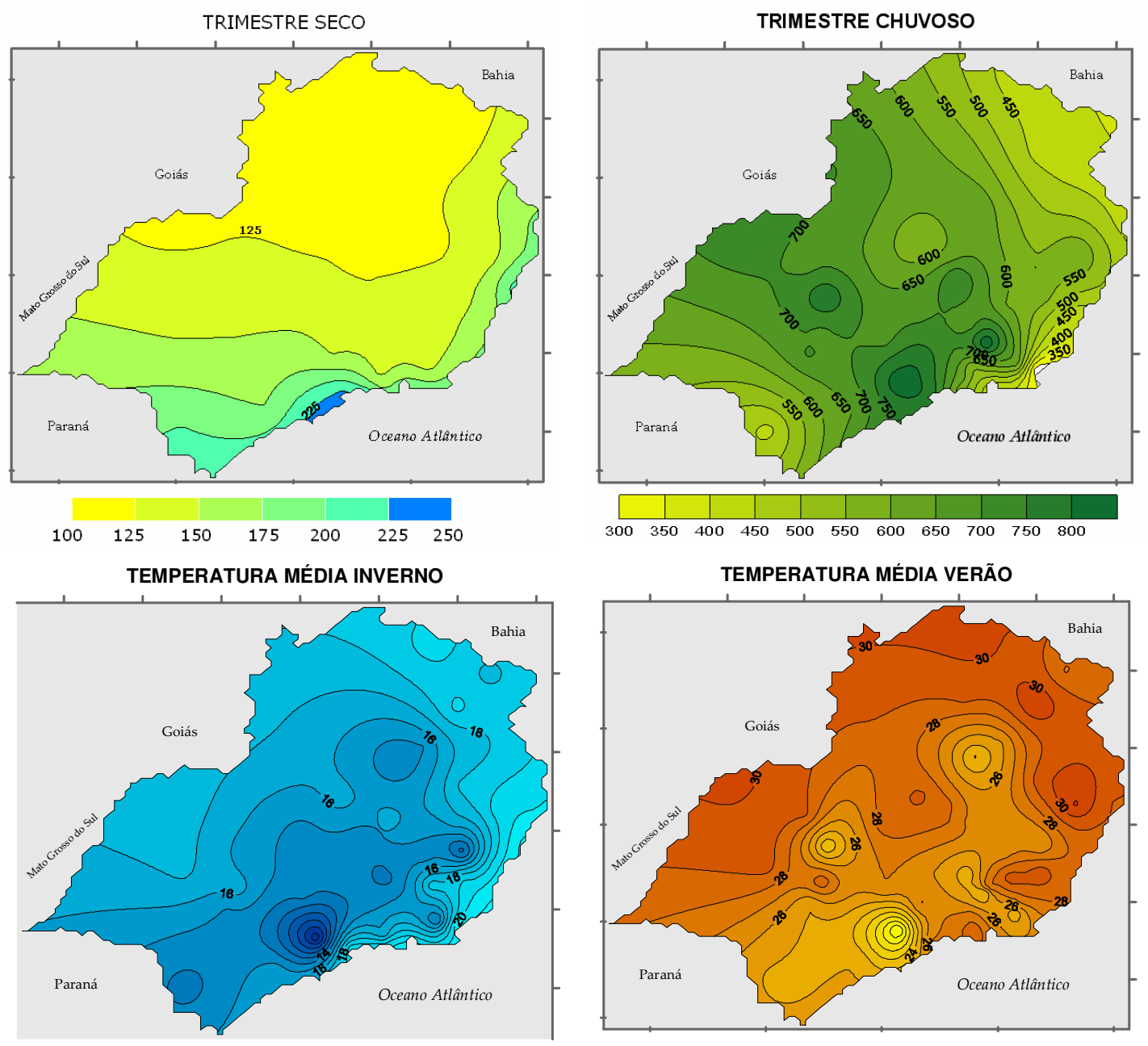

Figura 15. Precipitação e temperatura sazonais (verão e inverno).

Além desta diversidade, os fatores dinâmicos da atmosfera, em áreas de transição zonal dos climas globais, como é o caso de grande parte da região Sudeste, afetam a regularidade e a previsibilidade das condições do tempo e do clima, tanto de curto, quanto de longo prazo.

Sob uma aparente regularidade climática, a distribuição interanual das chuvas demonstra que num período de quase 40 anos é possível observar a sucessão de anos verões e invernos secos e úmidos, como no exemplo de Presidente Prudente (figura 16). Nota-se grande irregularidade pluviométrica, apesar de uma tendência geral de períodos mais secos entre junho e agosto.

A variação das temperaturas médias mensais, entretanto, parece ser mais regular, ainda que em alguns anos, os verões e invernos sejam mais rigorosos (figura 17 ). 


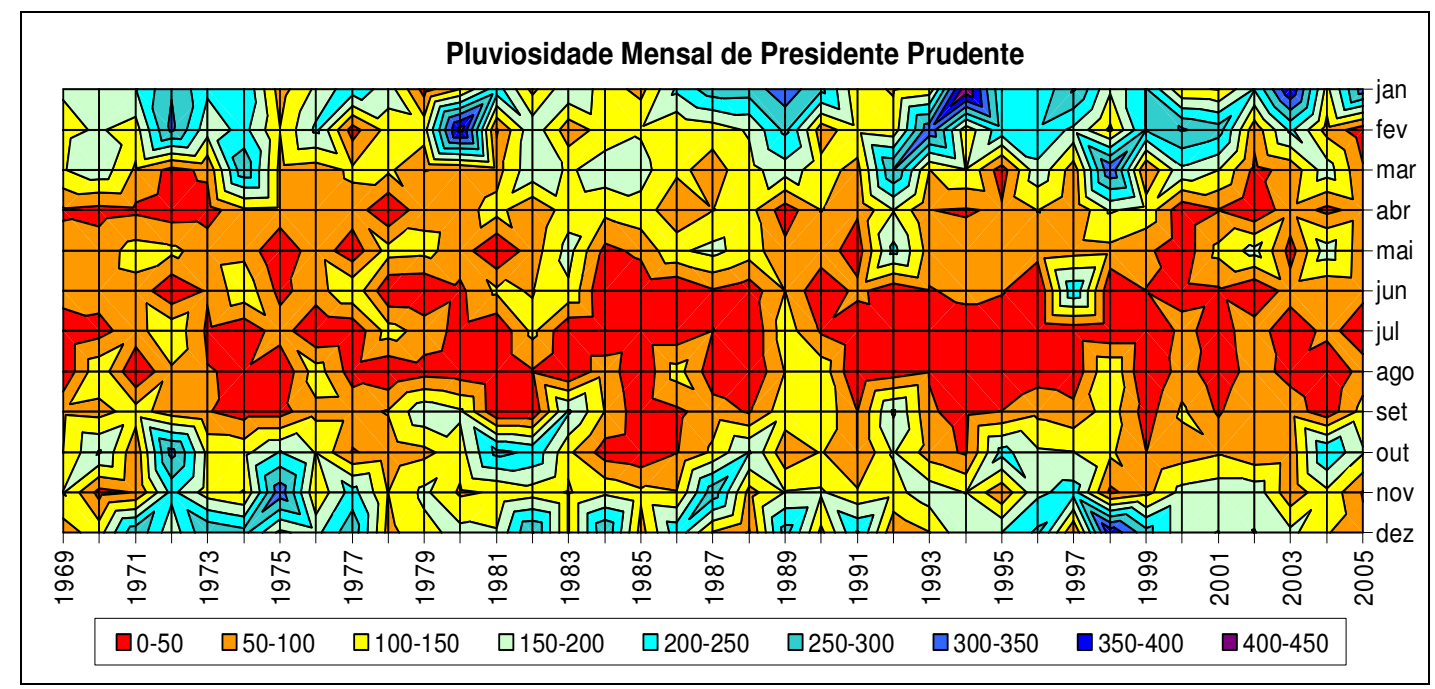

Figura 16. Pluviosidade mensal de Presidente Prudente.

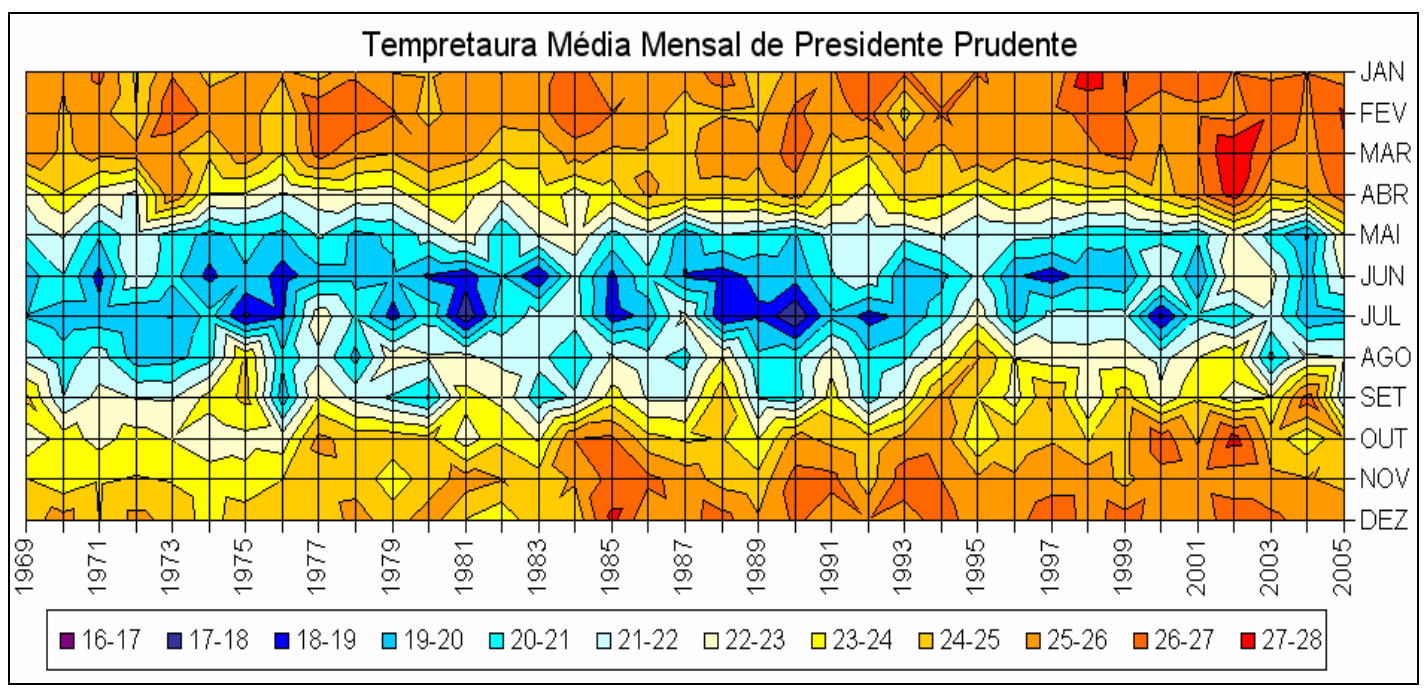

Figura 17. Temperatura média mensal de Presidente Prudente.

\section{As derivações antropogênicas}

(ou como a sociedade tem produzido o clima)

A região sudeste é a segunda menor das regiões brasileiras, compreendendo menos de $15 \%$ do território nacional, entretanto concentra quase metade da população do país, cerca de 80 dos 185 milhões. Três das maiores áreas metropolitanas do Brasil, localizam-se no sudeste: São Paulo, Rio de Janeiro e Belo Horizonte que, juntas concentram quase 35 milhões de habitantes. Dos mais de 1.500 municípios, pelo menos 80 tem população superior a 100.000 habitantes (figura 18).

Mais de $90 \%$ de seu território se encontra sem a vegetação natural primitiva, marcado por uma variada gama de paisagens antrópicas, notadamente. As pastagens e as monoculturas da cana-de-açúcar, café, laranja, milho e soja. 


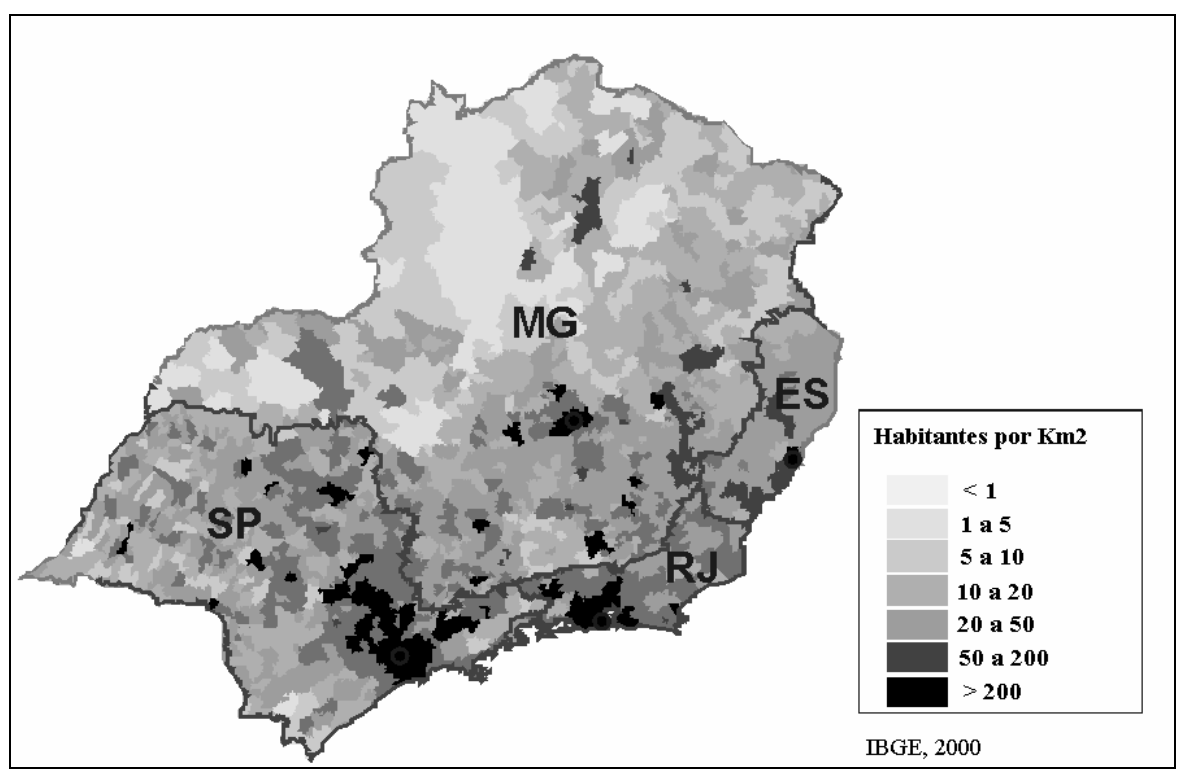

Figura 18. Densidade demográfica (IBGE, 2000).

A substituição das matas nativas pela atividade agropecuária tem modificado substancialmente a interação entre a atmosfera e a superfície. A título de exemplo, neste último século, a expansão territorial urbana da metrópole paulista e o crescimento populacional de menos de 200.000 habitantes no final do século XIX para quase 20 milhões de habitantes no início do século XXI, provocou um aumento de cerca de $2^{\circ} \mathrm{C}$ na temperatura média, como se pode observar na figura 19.

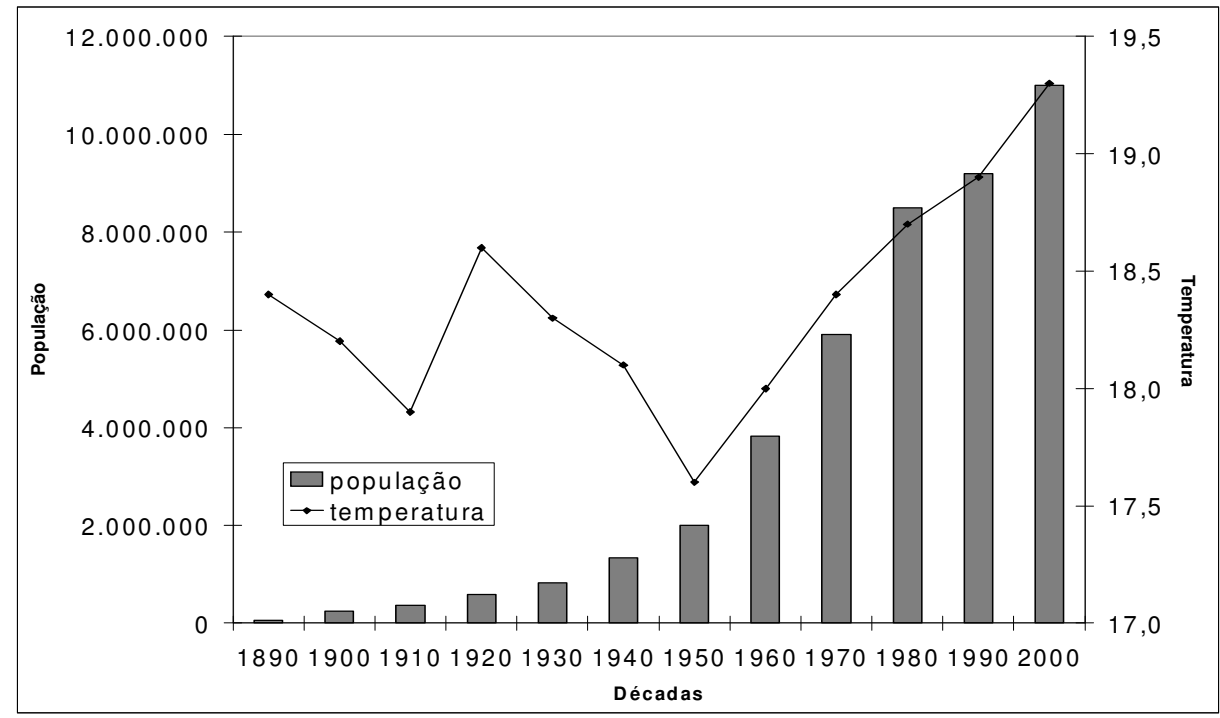

Figura 19. Crescimento populacional e médias térmicas decadais para a cidade de São Paulo.

As áreas dos principais centros urbanos têm verificado elevação da temperatura (entre $2^{\circ}$ e $3^{\circ} \mathrm{C}$ nas últimas 3 décadas). As precipitações totais 
anuais aumentaram cerca de $12 \%$ (1971 a 2000), porém, estão mais concentradas provocando episódios adversos comprometedores da integridade urbana.

\section{Conclusões}

Significativas variações no regime pluviométrico e no ritmo térmico têm sido verificadas nos climas da região Sudeste.

Com o aumento da rede meteorológica de superfície e, do alongamento das séries históricas dos dados de informação, já é possível verificar as anomalias nos climas regionais e compará-los ao período anterior.

Desde o trabalho de Nimer (1971), nenhum outro caracterizou os climas da região Sudeste. Entretanto, o conjunto de estudos de caso e dos climas locais, já forma um significativo acervo de informações que possibilitam uma re-análise dos climas do Sudeste.

\section{Referências Bibliográficas}

AB'SABER, A.N. Domínios morfoclimáticos e províncias fitogeográficas do Brasil. In: Orientação, n. 3, São Paulo: IGEOG/USP, 1967.

AZEVEDO, A. de. Regiões climato-botânicas do Brasil. Boletim Paulista de Geografia, São Paulo, n. 6, 1950.

BARBIERE, E.B. Ritmo climático e extração do sal em Cabo Frio. Revista Brasileira de Geografia, Rio de Janeiro, ano 37, n. 4, p. 23-109, 1975.

BARRA, L.P. Breve estudo das chuvas na cidade de Campinas - 1890-1940. In: Congresso Brasileiro de Geografia, 10, 1944, Belém. Anais: Rio de Janeiro, 1942. p. 557-572.

BERNARDES, L.M.C. Clima do Brasil. Boletim Geográfico, Rio de Janeiro, vol. 9, n. 103, p. 727-739, 1951.

- Tipos de clima do estado do Rio de Janeiro. Separata da Revista Brasileira de Geografia, Rio de Janeiro, vol. 14, n. 1, 1953.

CAMARA, N. S. Os insumos climáticos no sistema de produção do trigo no estado de São Paulo.São Paulo, 1977. Dissertação (Mestrado em Geografia Física) USP/FFLCH. Inédita

CONTI, J.B. Circulação secundária e efeito orográfico na gênese das chuvas na região lesnordeste paulista. Série Teses e Monografias, São Paulo, n. 18, 1975. 82 p.

DE MARTONNE, E. Problemas morfológicos do Brasil tropical atlântico. In: Revista Brasileira de Geografia, Rio de Janeiro: IBGE, ano VI, vol. 2, 1944.

ELY, D.F. Teoria e método da climatologia geográfica brasileira. Presidente Prudente, 2006. Tese (Doutorado em Geografia), UNESP/FCT. Inédita

FERRAZ, J. de S. Subsídios para o estudo de um ciclo climático do Sueste Brasileiro. Revista Brasileira de Geografia, Rio de Janeiro, vol. 2., 1939.

Ligeiro esboço de alguns aspectos fundamentais da climatologia do Estado de São Paulo. In: Congresso Brasileiro de Geografia, 9, 1940, Florianópolis. Anais, Rio de Janeiro, 1942. vol. 2, p. 425-439.

FRANÇA, A. Estudo sobre o clima da Bacia de São Paulo. Boletim da Faculdade de Filosofia, Ciências e Letras, n. 70, São Paulo: USP, 1946. (Tese de Doutorado)

GUIMARÃES, F. de M.S. Clima do Brasil. Boletim Geográfico, Rio de Janeiro, vol. 3, n. 27, p. 417-433, 1945.

IBGE. Instituto Brasileiro de Geografia e Estatística. www.ibge.gov.br (acessado em 27 de junho de 2006.

MONTEIRO, C.A. de F. A frente polar atlântica e as chuvas de inverno na fachada sul- 
oriental do Brasil. Série Teses e Monografias, São Paulo:USP/Igeog, n. 1, 1969. 68 p. - A dinâmica climática e as chuvas no Estado de São Paulo. São Paulo: Fapesp/USP/Igeog, 1973. 129 p.

. Teoria e clima urbano. Série Teses e Monografias, São Paulo:USP/Igeog, n. 25, 1976a. $181 \mathrm{p}$.

Clima e excepcionalismo: conjecturas sobre o desempenho da atmosfera como fenômeno geográfico. Florianópolis: UFSC, 1991. 241p.

MORIZE, H. Esboço da climatologia do Brazil. R.de Janeiro: Observatório Astronômico, 1889.

NIMER, E. Clima da região Sudeste. In: Geografia do Brasil. Rio de Janeiro/IBGE, 1971

Climatologia do Brasil. Rio de Janeiro: IBGE, 1979.

PEIXOTO, A. Climatologia do Brasil. Rio de Janeiro: Imprensa Nacional, 1908.

SANT'ANNA NETO, J.L. Ritmo climático e a gênese das chuvas na zona costeira paulista. São Paulo, 1990. Dissertação (Mestrado em Geografia Física), USP/FFLCH. Inédita . As chuvas no Estado de São Paulo. São Paulo, 1995. Tese (Doutorado em Geografia Física), USP/FFLCH. Inédita ; ZAVATINNI, J.A. Variabilidade e mudanças climáticas: implicações ambientais e socioeconômicas. Maringá: Eduem, 2000. 259 p.

SEREBREBICK, S. Classificação meteorológica dos climas do Brasil. In: Congresso Brasileiro de Geógrafos, 9, 1940, Florianópolis, Anais: Rio de Janeiro: CNG/IBGE, vol. 2, p. 440-459.

SERRA, A.; RATISBONNA, L. As ondas de frio da bacia amazônica. Rio de Janeiro: Ed. do Serviço de Meteorologia, 1942a.

Serviço de Meteorologia, 1942b.

As massas de ar da América do Sul. Rio de Janeiro: Ed. do Montevidéu, 1942.

. Os regimes das chuvas da América do Sul. Revista Meteorológica,

SETZER, J. O Clima do Estado de São Paulo. Boletim Geográfico, Rio de Janeiro, vol. 19, 1944.

STERNBERG, H. O'Reilly. Enchentes e movimentos coletivos de solo no Vale do Paraíba em dezembro de 1948. Revista Brasileira de Geografia, Rio de Janeiro, vol. 11, n. 2, p. 223-261, 1949.

TARIFA, J.R. Sucessão de tipos de tempo e variação do balanço hídrico no extremo oeste paulista. Série Teses e Monografias, São Paulo, n. 8, 1973. 71 p.

Fluxos polares e as chuvas de primavera - verão no estado de São Paulo. Série Teses e Monografias, São Paulo, n. 19, 1975.

TORRES, M.; FERRAZ, J. de S. Contribuição para o estudo do regime das chuvas no Nordeste Brasileiro. In: Congresso Brasileiro de Geógrafos, 9, 1940, Florianópolis. Anais: Rio de Janeiro: CNG/IBGE, 1942. vol. 2, p. 401-424

ZAVATINNI, J.A. Desenvolvimento e perspectivas da climatologia geográfica no Brasil: o enfoque dinâmico, a noção de ritmo climático e as mudanças climáticas. In: João L. Sant'Anna Neto e João A. Zavatini (orgs) Variabilidade Mudanças Climáticas. Maringá: EDUEM, 2000. p. 225-252

\section{Agradecimentos}

Este trabalho é dedicado a Edmon Nimer (in memoriam), a Carlos Augusto de Figueiredo Monteiro e a Javier Martin-Vide, geógrafos que souberam traduzir, com razão e emoção, a complexidade do clima na perspectiva geográfica.

O autor manifesta, também, a sua gratidão ao colega Newton Brigatti pela elaboração das cartas climáticas. 